\title{
Turbulent Humidity Fluctuations in the Convective Boundary Layer: Case Studies Using Water Vapour Differential Absorption Lidar Measurements
}

\author{
Shravan Kumar Muppa ${ }^{1}$ - Andreas Behrendt ${ }^{1}$ - Florian Späth ${ }^{1}$ • \\ Volker Wulfmeyer $^{1}$ - Simon Metzendorf ${ }^{1}$ - Andrea Riede ${ }^{1}$
}

Received: 24 October 2014 / Accepted: 26 August 2015 / Published online: 9 September 2015

(C) The Author(s) 2015. This article is published with open access at Springerlink.com

\begin{abstract}
Turbulent humidity fluctuations in the convective boundary layer (CBL) under clear-sky conditions were investigated by deriving moments up to fourth-order. Highresolution humidity measurements were collected with a water vapour differential absorption lidar system during the $\mathrm{HD}(\mathrm{CP})^{2}$ Observational Prototype Experiment (HOPE). Two cases, both representing a well-developed CBL around local noon, are discussed. While the first case (from the intensive observation period (IOP) 5 on 20 April 2013) compares well with what is considered typical CBL behaviour, the second case (from IOP 6 on 24 April 2013) shows a number of non-typical characteristics. Both cases show similar capping inversions and wind shear across the CBL top. However, a major difference between both cases is the advection of a humid layer above the CBL top during IOP 6. While the variance profile of IOP 5 shows a maximum at the interfacial layer, two variance peaks are observed near the CBL top for IOP 6. A marked difference can also be seen in the third-order moment and skewness profiles: while both are negative (positive) below (above) the CBL top for IOP 5, the structure is more complex for IOP 6. Kurtosis is about three for IOP 5, whereas for IOP 6 , the distribution is slightly platykurtic. We believe that the entrainment of an elevated moist layer into the $\mathrm{CBL}$ is responsible for the unusual findings for IOP 6, which suggests that it is important to consider the structure of residual humidity layers entrained into the CBL.
\end{abstract}

Keywords Convective boundary layer - Differential absorption lidar - Skewness · Turbulence . Variance profiles

\section{Introduction}

Turbulence is responsible for the vertical transport of heat and moisture in the convective boundary layer (CBL). The fluxes of heat and moisture have been investigated quite exten-

Shravan Kumar Muppa

shravan.muppa@uni-hohenheim.de

1 Institute of Physics and Meteorology, University of Hohenheim, Garbenstrasse 30, 70599 Stuttgart, Germany 
sively in the surface layer near the ground (Stull 1988), but remain poorly understood in the upper part of the CBL and especially at the interface of the CBL and the free troposphere, the so-called interfacial layer, where turbulent fluctuations are greatest due to entrainment (Kaimal et al. 1976). An adequate representation of the thermodynamic structure of the CBL in atmospheric models is critical; moisture transport across the CBL influences not only the formation of fair-weather cumuli (Zhu and Albrecht 2002) but also the initiation of deep convection and flash floods (Weckwerth 2000; Behrendt et al. 2011; Corsmeier et al. 2011; Stevens and Bony 2013). Consequently, several large international experiments aimed at a better understanding of the humidity field in the CBL have been carried out, e.g. the Mesoscale Alpine Program for high mountains during the 1990s (Richard et al. 2007); the International $\mathrm{H}_{2} \mathrm{O}$ Project (IHOP_2002) in 2002 (Weckwerth et al. 2004), and the Convective and Orographically-induced Precipitation Study (COPS) in 2007 (Wulfmeyer et al. 2011). Recently, the High Definition Clouds and Precipitation for advancing Climate Prediction $\left(\mathrm{HD}(\mathrm{CP})^{2}\right)$ project was initiated in Germany, which has a goal to investigate whether the simulation of clouds and precipitation can be improved by finer grid increments of the order of $1 \mathrm{~km}$ or less (see www.hdcp2.eu). The $\mathrm{HD}(\mathrm{CP})^{2}$ Observation Prototype Experiment (HOPE), conducted in spring 2013, was dedicated to providing high resolution datasets of meteorological variables at the subgrid scale that are subject to parametrizations in the high resolution models of $\mathrm{HD}(\mathrm{CP})^{2}$.

Studies based on large-eddy simulation (LES) have been widely used to investigate the characteristics of turbulence in the CBL (Deardorff 1974; Deardorff et al. 1980; Wyngaard and Brost 1984; Moeng and Wyngaard 1984; Sorbjan 1996, 1999, 2006; Sullivan et al. 1998). For improved turbulence parametrization schemes, general scaling relationships between the higher-order moments of temperature and humidity fluctuations in the CBL and their vertical gradients in the interfacial layer need to be investigated (Sorbjan 2005; Wulfmeyer et al. 2015). However, present LES studies show a significant uncertainty in their results due to processes at the subgrid scale (Stevens and Lenschow 2001; Zhou et al. 2014). Sullivan and Patton (2011) have shown that turbulent eddies in the middle of the CBL can be resolved with horizontal and vertical grid lengths of $25 \mathrm{~m}$, but there are still significant challenges in modelling the entrainment zone where an even higher resolution is required. This underlines the importance of validating the LES results with corresponding measurements. Vertical motions and their effect on the entrainment in the CBL have been investigated (Hogan et al. 2009; Lenschow et al. 2012), but studies focusing on water vapour exchange at the CBL top are sparse. Recently, Moeng and Arakawa (2012) highlighted the importance of moisture transport at the subgrid scale in the planetary boundary layer (PBL) with respect to cloudresolving models.

Earlier observations of the humidity structure in the CBL were mainly based on aircraft in situ data and radiosondes. The latter provide a snapshot of the CBL profile and thus do not capture the mean profiles needed for comparisons with models (Weckwerth et al. 1996) nor can they provide information on turbulent fluctuations. The characteristics of humidity fluctuations in the CBL have been studied using in situ measurements (Mahrt 1976, 1991; Lenschow et al. 1994) and active remote sensing techniques, particularly water vapour differential absorption lidar (DIAL) (Kiemle et al. 1997; Wulfmeyer 1999a, b; Giez et al. 1999; Behrendt et al. 2011) and water vapour Raman lidar (Wulfmeyer et al. 2010; Turner et al. 2014). Airborne measurements reveal spatially-averaged properties of the CBL but only at low vertical resolution. Furthermore, the operation of research aircraft is expensive and simultaneous observations at all heights in the CBL are not possible. Remote sensing techniques overcome these limitations and cover larger ranges simultaneously and continuously. Monitoring moisture fluctuations with high resolution for turbulence studies is a challenging 
task due to the noise limitation of these instruments; nevertheless, new techniques based on lidar are capable of providing data with sufficient precision and accuracy (Lenschow et al. 2000; Wulfmeyer et al. 2010, 2015).

Couvreux et al. (2005) compared the results of airborne water vapour DIAL measurements from the IHOP campaign with LES for a growing CBL. They found in both observations and LES that dry downdrafts entrained from above the CBL govern the integral scale of moisture variability in the CBL. Later, this study was further extended to the analysis of skewness profiles (Couvreux et al. 2007), showing that dry tongues contribute significantly to the turbulent transport from the top of the CBL into its interior. Wind shear at the interfacial layer also plays an important role in the dynamics and growth of the CBL (Conzemius and Fedorovich 2006; Sorbjan 2006; Fedorovich and Conzemius 2008; Wulfmeyer et al. 2015). However, the role of wind shear on the profile of humidity variance and skewness in the CBL has so far not been investigated in detail. Furthermore, there are only a few studies discussing the influence of elevated dry and moist layers on the turbulent humidity fluctuations and their statistics. Van Heerwaarden et al. (2009) underlined the importance of accurate moisture profiles to properly represent dry air entrainment for understanding cloud formation under moist and dry tropospheric conditions. Recently, Bennett et al. (2010) investigated the vertical and horizontal distributions of humidity in the nocturnal boundary layer (NBL), as well as the evolution and growth of the CBL during the formation of open-cell convection. They found that the advection of drier air into the region resulted in a humidity minimum in the middle and a peak at the top of the residual layer. Grossman and Gamage (1995) observed similar drying in the lower part of the mixed layer and moistening at the top, when an elevated mixed layer was entrained into the CBL. In the current study, we use high-resolution observations to investigate the role of turbulent processes in the CBL humidity structure during such cases.

We present results obtained with recent data from our ground-based, scanning water vapour DIAL system (Wagner et al. 2013). Whereas it is also possible to derive higher-order moments with water vapour Raman lidar, Wulfmeyer et al. (2010) and Turner et al. (2014) demonstrated that the noise level in daytime turbulence profiles is much larger than for water vapour DIAL. Therefore, water vapour Raman lidar turbulence profiles are strongly limited to measurements of third- and fourth-order moments. Our water vapour DIAL uses a high power laser and a very efficient receiver that yields high-resolution data with low noise in the CBL including the interfacial layer. For the two CBL cases presented, turbulent moments were derived from water vapour DIAL data, including reliable skewness, fourth-order, and kurtosis profiles. We further discuss the effect of boundary-layer height, entrainment zone thickness, humidity gradient across the CBL top, and surface latent heat fluxes on the humidity variance profile in the CBL.

This paper is structured as follows. In Sect. 2, we provide a short description of the measurement campaign HOPE, with details of the DIAL system used for the measurements and the properties important for the retrieval of absolute humidity from DIAL given in Sect. 3. A detailed overview of meteorological conditions during the two intensive observation periods (IOPs) selected is given in Sect. 4. The case studies presented here focus on a welldeveloped CBL under different forcing conditions. Section 5 describes the methodology for deriving the higher-order moments and in Sect. 6, higher-order moments such as the variance, skewness, and kurtosis are presented for both cases. Our findings are compared with previous studies based on observations and LES and are discussed in Sect. 7. Finally, the results are summarized in Sect. 8. 


\section{The HOPE Campaign}

A new model for high-resolution weather forecasts will be developed and verified in the $\mathrm{HD}(\mathrm{CP})^{2}$ project. The main aim of the HOPE campaign was to collect high-resolution datasets that will be used for the $\operatorname{HD}(\mathrm{CP})^{2}$ model initialization and output evaluation. The Institute of Physics and Meteorology (IPM) of University of Hohenheim (UHOH) operated its water vapour DIAL system at a site close to the village of Hambach near the research centre Jülich, Germany, at $50^{\circ} 53^{\prime} 50.56^{\prime \prime} \mathrm{N}, 6^{\circ} 27^{\prime} 50.39^{\prime \prime} \mathrm{E}, 110 \mathrm{~m}$ above sea level. In addition to the DIAL, IPM used a rotational Raman lidar for temperature measurements (Hammann et al. 2015; Behrendt et al. 2015) and the Karlsruhe Institute of Technology (KIT) operated its KITcube (Kalthoff et al. 2013), a suite of instruments including a Doppler lidar (Träumner et al. 2014), at the same site. Radiosondes were launched at this site regularly at 1100 and 2300 UTC during the HOPE campaign and more often during IOPs. In addition to the so-called supersite near Hambach, there were two more supersites in the HOPE area forming a triangle of about 4-km side length, but none of the other sites was equipped with a water vapour DIAL.

\section{The UHOH Water Vapour DIAL System}

The water vapour DIAL system is a unique remote sensing tool for deriving absolute humidity profiles with high temporal and spatial resolution in the lower troposphere (Wulfmeyer and Bösenberg 1998). During the HOPE campaign, the DIAL system was operated in the vertical steering mode during clear sky conditions and in scanning mode during cloudy periods. In total, the instrument collected $180 \mathrm{~h}$ of data during 18 IOP days with the focus on water vapour in the CBL. A detailed description of the UHOH DIAL system set-up during HOPE and the derivation of water vapour profiles is given in Späth et al. (2015). The operational wavelength of the UHOH DIAL is around $818 \mathrm{~nm}$, and the backscatter signals were recorded for each laser shot $(250 \mathrm{~Hz})$ with a range resolution of $15 \mathrm{~m}$ up to a range of $30 \mathrm{~km}$. The laser transmitter was switched in each shot between the online and offline frequencies. The measured absolute humidity has typical temporal and spatial resolutions of $1 \mathrm{~s}$ to $1 \mathrm{~min}$ and 15 to $300 \mathrm{~m}$, respectively, depending on the range of interest. Due to the instrument's high laser power (about $2 \mathrm{~W}$ ) in combination with a very efficient receiver (0.8-m telescope), the data have low noise errors up to the CBL top.

For the derivation of absolute humidity profiles, the following DIAL system and atmospheric properties are important: (1) the laser spectral properties with respect to frequency stability, bandwidth, and spectral purity, (2) the profile of the water vapour absorption cross-section, (3) the temporal variability of the aerosol backscatter coefficient between the online and offline laser pulses, and (4) the Rayleigh-Doppler effect (Ansmann 1985).

All these issues have been taken into account in our system design and methodology to derive accurate humidity profiles including a detailed error analysis. Concerning (1), the laser transmitter is based on an injection-seeding technology. Wagner et al. (2013) demonstrated that the UHOH DIAL transmitter has excellent spectral properties so that remaining systematic errors are $<3 \%$ throughout the troposphere. With respect to (2), detailed sensitivity analyses of systematic errors in the derivation of the absorption cross-section profile led to an error $<1.3 \%$ (with uncertainties of $1 \mathrm{~K}$ in temperature and $1 \mathrm{hPa}$ in pressure, respectively) for measurements in the lower troposphere. Tackling issue (3), the delay between the online and the offline laser pulses was $4 \mathrm{~ms}$, which leads to an air volume displacement of only 40 $\mathrm{mm}$ at a horizontal wind speed of $10 \mathrm{~m} \mathrm{~s}^{-1}$. Thus, considering the typical size of an eddy of several tens of $\mathrm{m}$ and a beam radius of $0.35 \mathrm{~m}$ at a height of $500 \mathrm{~m}$ above ground level, the 
10-s averages of online and offline backscatter coefficients are virtually the same. Therefore, systematic errors in the derivation of absolute humidity profiles due to (3) are negligible. The backscatter profiles were used to determine the instantaneous CBL top height with the Haar wavelet technique (Davis et al. 2000; Pal et al. 2010). Its average over the measurement period is an excellent approximation for the mean CBL top height $\left(z_{i}\right)$, which was used for normalizing the height of the turbulence profiles.

With respect to (4), great care has to be taken in the analysis of water vapour DIAL measurements due to Rayleigh-Doppler broadening of the backscattered signal. This effect needs to be considered at height levels where strong gradients in the aerosol backscatter data may be present such as the CBL top or aerosol layers in the free troposphere (Ansmann and Bösenberg 1987; Ismail and Browell 1989). The Rayleigh-Doppler effect can be investigated and corrected with a derived particle backscatter coefficient profile (Fernald 1984) and by determining the Rayleigh-Doppler term in the DIAL equation. With our system set-up, where the online frequency of the water vapour DIAL laser transmitter was tuned at the wing of the water vapour line, the evaluation of the Rayleigh-Doppler term shows a negative correction with a backscatter gradient on the order of $0.4 \mathrm{~g} \mathrm{~m}^{-3}$ (corresponding to a relative correction of about $7 \%$ ). At first glance, this may lead to the conclusion that the Rayleigh-Doppler correction is negligible. However, it was found that this correction needs to be applied for accurate profiling of higher-order moments, particularly in the interfacial layer, due to the non-linearity of the correction in the region of the backscatter gradient. Thus, we applied the Rayleigh-Doppler correction to all derivations of water vapour profiles and performed a thorough sensitivity analysis with respect to remaining errors due to the Rayleigh-Doppler correction. For this purpose, we varied the parameters used for deriving the particle backscatter profiles between 20 and $40 \mathrm{sr}$ for the lidar ratio and $0-10^{-8} \mathrm{~m}^{-1} \mathrm{sr}^{-1}$ for the initialization of the inversion at a height of $2700 \mathrm{~m}$. We found that the effect of these variations is negligible, e.g. the difference in the derivation of the absolute humidity profiles was $<0.01 \mathrm{~g} \mathrm{~m}^{-3}$.

A window length of $135 \mathrm{~m}$ was used for the Savitzky-Golay (SaGo) algorithm (Savitzky and Golay 1964) when deriving absolute humidity from the UHOH DIAL data. For all turbulence analyses, we used a temporal resolution of $10 \mathrm{~s}$, corresponding to 1250 online and offline laser shots, respectively. The high accuracy of our measurements was also confirmed by several intercomparison campaigns. An extensive comparison between the UHOH water vapour DIAL and six other water vapour lidar systems was performed by Bhawar et al. 2011 during the COPS project, who found a mean bias of $1.4 \%$ for the UHOH water vapour DIAL.

\section{Meteorological Conditions}

\subsection{Case 1: IOP 5, 20 April 2013}

For IOP 5, the HOPE domain was in the transition region between an anticyclone with its centre located over the Baltic Sea along the coast of the Netherlands to the south-west and a cold front over the Alps to the south-east. An upper-air warm front was observed to the north. Figure 1 shows the European Centre for Medium-Range Weather Forecasting (ECMWF) reanalysis data at $850 \mathrm{hPa}$ for specific humidity and the horizontal wind vector during both IOPs. For IOP 5, specific humidity at $850 \mathrm{hPa}$ over the measurement site was relatively low and very dry air was advected into the region. Figure 2 a shows the particle backscatter coefficient profiles measured with DIAL between 1130 and 1330 UTC for IOP 5. The free troposphere was mainly clear with only very weak aerosol layers; higher aerosol content was 

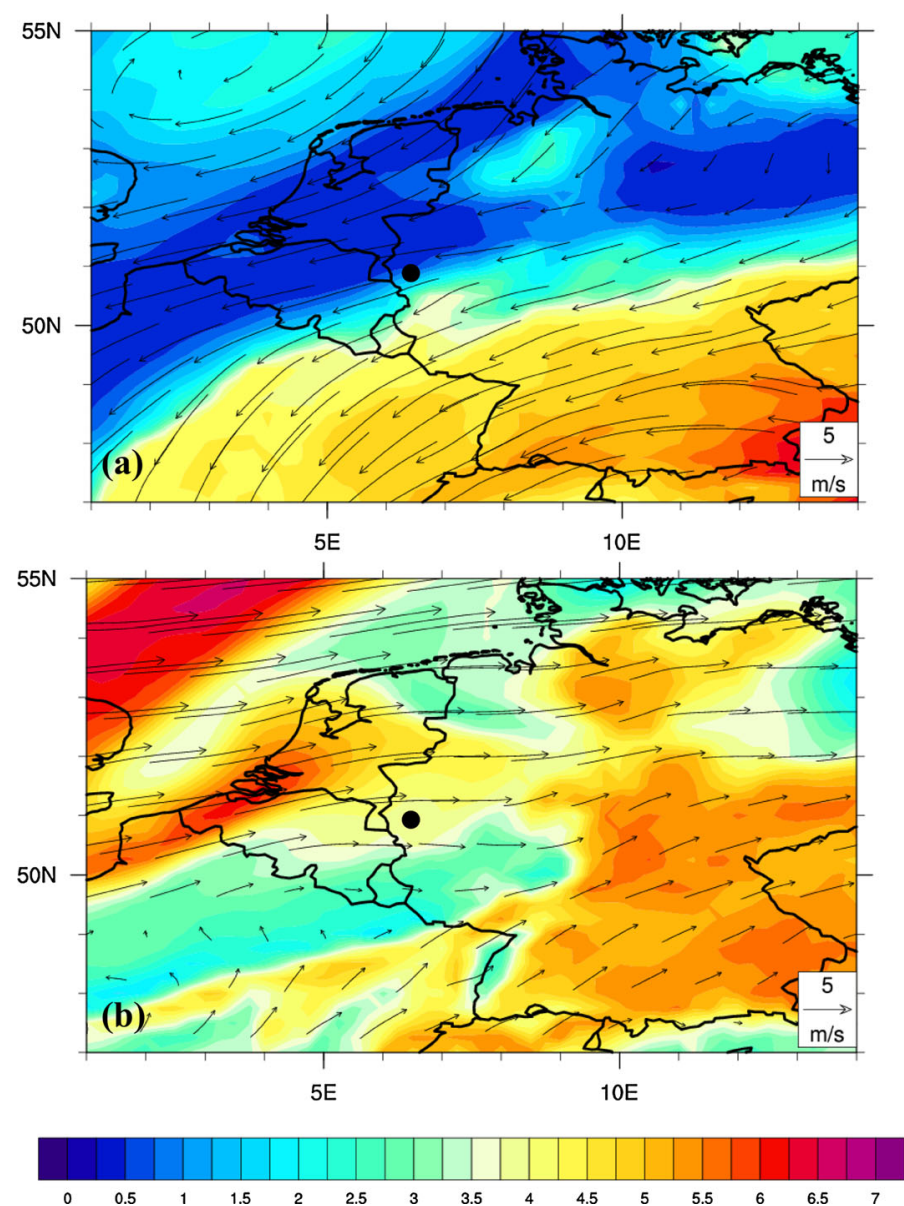

Fig. 1 Meteorological conditions based on ECMWF 850-hPa analysis on a 20 April 20131200 UTC, b 24 April 20131200 UTC. Colour scale indicates specific humidity $\left(\mathrm{g} \mathrm{kg}^{-1}\right)$; black arrows represent horizontal wind speed $\left(\mathrm{m} \mathrm{s}^{-1}\right)$. Black dot shows the measurement site

found in the CBL. The period from 1130 to 1330 UTC was selected for the analysis of the higher-order moments and includes local noon at 1134 UTC. The CBL was well developed and became quasi-stationary. Absolute humidity along with the instantaneous CBL top height during the selected period are shown in Fig. 2b. Absolute humidity was around $3.5 \mathrm{~g} \mathrm{~m}^{-3}$ in the CBL at 1130 UTC and then decreased to about $3 \mathrm{~g} \mathrm{~m}^{-3}$ by 1330 UTC. This drying was due to a combination of entrainment of drier air into the CBL and vertical transport of moisture by thermals. The mean of the instantaneous CBL top heights over the selected period, $z_{i}$, was $1295 \mathrm{~m}$ with a standard deviation of $86 \mathrm{~m}$; the smallest and largest values of the instantaneous CBL heights were 1110 and $1470 \mathrm{~m}$, respectively. We later used the $z_{i}$ for normalizing the height scales. The mean entrainment zone thickness (EZT) is estimated using the cumulative frequency distribution of the instantaneous CBL top height (Pal et al. 2010). The mean EZT during the period was $73 \mathrm{~m}$. Latent and sensible heat fluxes at the surface were 100 and $255 \mathrm{~W} \mathrm{~m}^{-2}$ during the period selected for the higher-order moment analysis. 

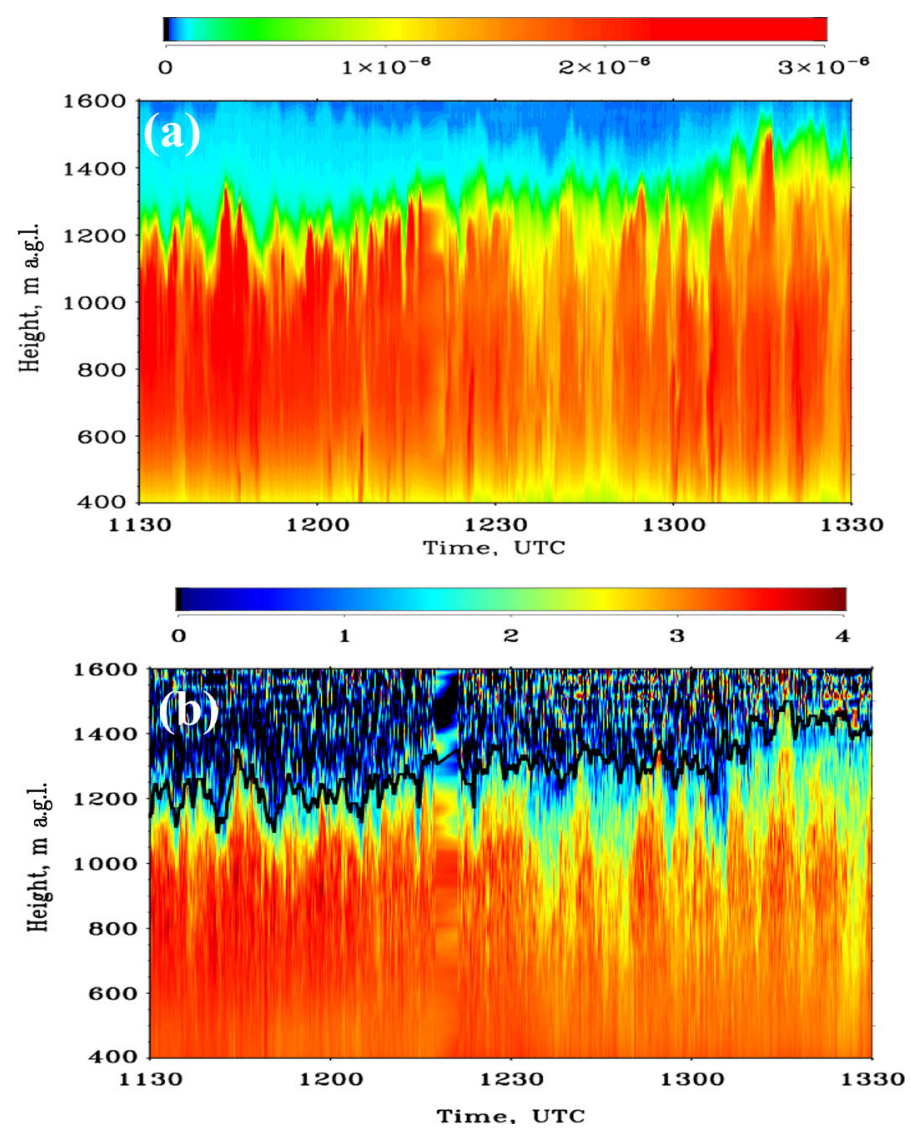

Fig. 2 a Particle backscatter coefficient in $\mathrm{m}^{-1} \mathrm{sr}^{-1}$ of the UHOH WVDIAL with resolutions of $10 \mathrm{~s}$ and 15 $\mathrm{m}$ for IOP 5 on 20 April 2013, 1130-1330 UTC. b Absolute humidity measurements in $\mathrm{g} \mathrm{m}^{-3}$ of the UHOH DIAL (10-s and 67.5-m resolution) for the same period with instantaneous CBL heights shown as a black solid line

\subsection{Case 2: IOP 6, 24 April 2013}

The HOPE domain was under the influence of an anticyclone located over central Europe during IOP 6. The ECMWF 850-hPa specific humidity indicates that moist air was advected from the south-west towards the measurement site (Fig. 1b). Figure $3 \mathrm{a}$ shows the UHOH DIAL particle backscatter coefficient for the period from 1100 to 1200 UTC for IOP 6 (same resolutions as Fig. 2a). The CBL was well developed by 1000 UTC, with an elevated aerosol layer found above the CBL top around $1400 \mathrm{~m}$. We selected the period from 1100 to 1200 UTC around local noon for the analysis of higher-order moments. Figure 3b shows the UHOH DIAL absolute humidity during this period, with values in the CBL around $7 \mathrm{~g} \mathrm{~m}^{-3}$, almost twice as high as for IOP 5 . The absolute humidity in the lower free troposphere was around $3.5 \mathrm{~g} \mathrm{~m}^{-3}$, i.e. much higher than for IOP 5. A dry layer was present at $1100-1200 \mathrm{~m}$ around 0900 UTC, with a moist layer above it (1200-1400 m). As the CBL developed, these layers were entrained into the CBL by 1100 UTC. A humidity minimum was found below the CBL top, with humidity increasing above it, similar to observations of 

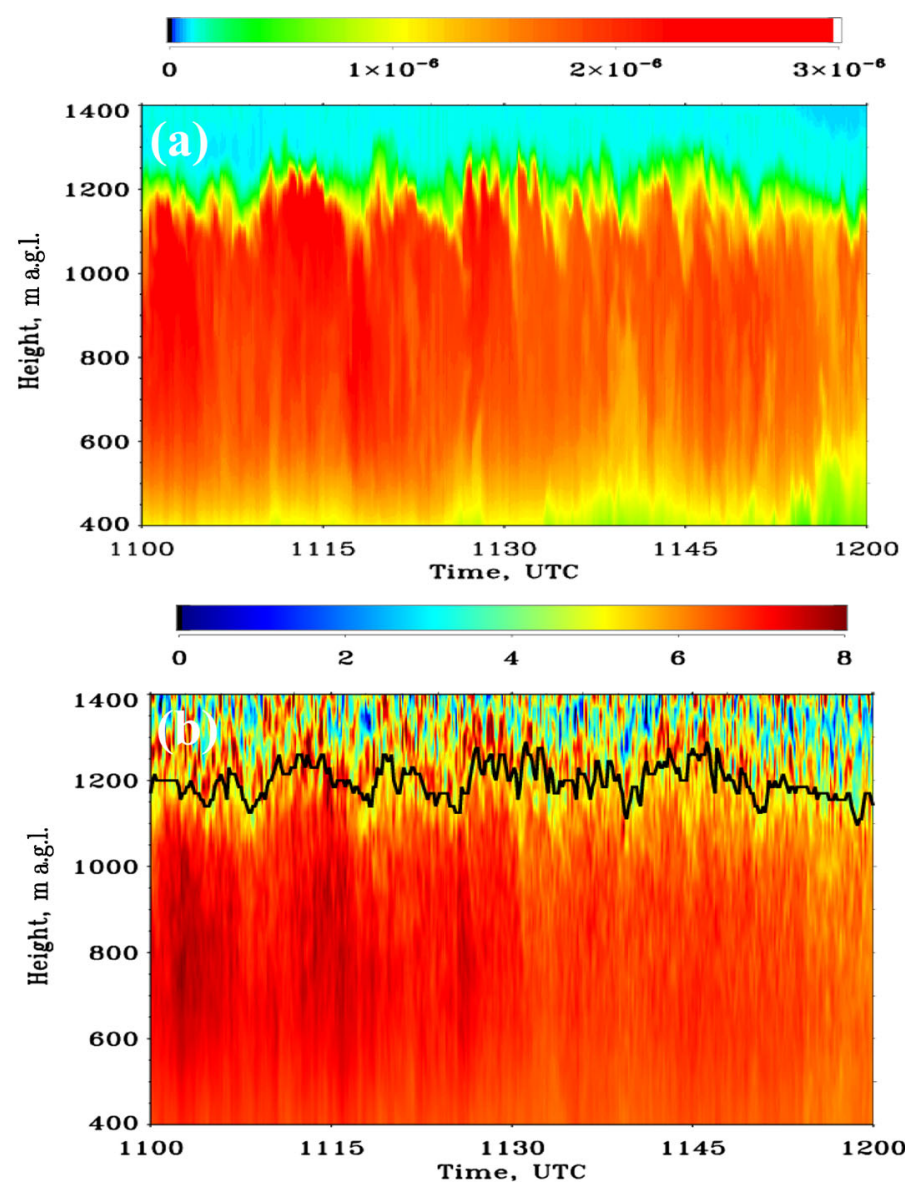

Fig. 3 Same as Fig. 2 but for IOP 6 on 24 April 2013, 1100-1200 UTC

Bennett et al. (2010) where an elevated mixed layer was entrained into the growing CBL during the morning transition period. The mean height of the mixed layer during the selected period was $1200 \mathrm{~m}$ with a standard deviation of $39 \mathrm{~m}$ and minimum and maximum values of 1125 and $1275 \mathrm{~m}$, respectively. The mean EZT during this period was $36 \mathrm{~m}$. Accordingly, the CBL top was about $100 \mathrm{~m}$ lower than for IOP 5 and the spread of the instantaneous CBL top heights was reduced by a factor of two. Sensible heat flux $\left(192 \mathrm{~W} \mathrm{~m}^{-2}\right)$ was lower and latent heat flux $\left(255 \mathrm{~W} \mathrm{~m}^{-2}\right)$ was higher for IOP 6 when compared to IOP 5.

\subsection{Radiosoundings}

Figure 4 shows profiles of various meteorological parameters from radiosoundings launched at the measurement site for IOP 5 at 1300 UTC and for IOP 6 at 1100 UTC. The heights of occurrence of large gradients in the potential temperature and humidity profiles from the radiosondes agree roughly with the $z_{i}$ values. It should be noted that the radiosonde profiles were measured at specific times while the lidar-derived $z_{i}$ values are averages over our analysis periods. The characteristics of the two IOP days are summarized in Table 1 . The 

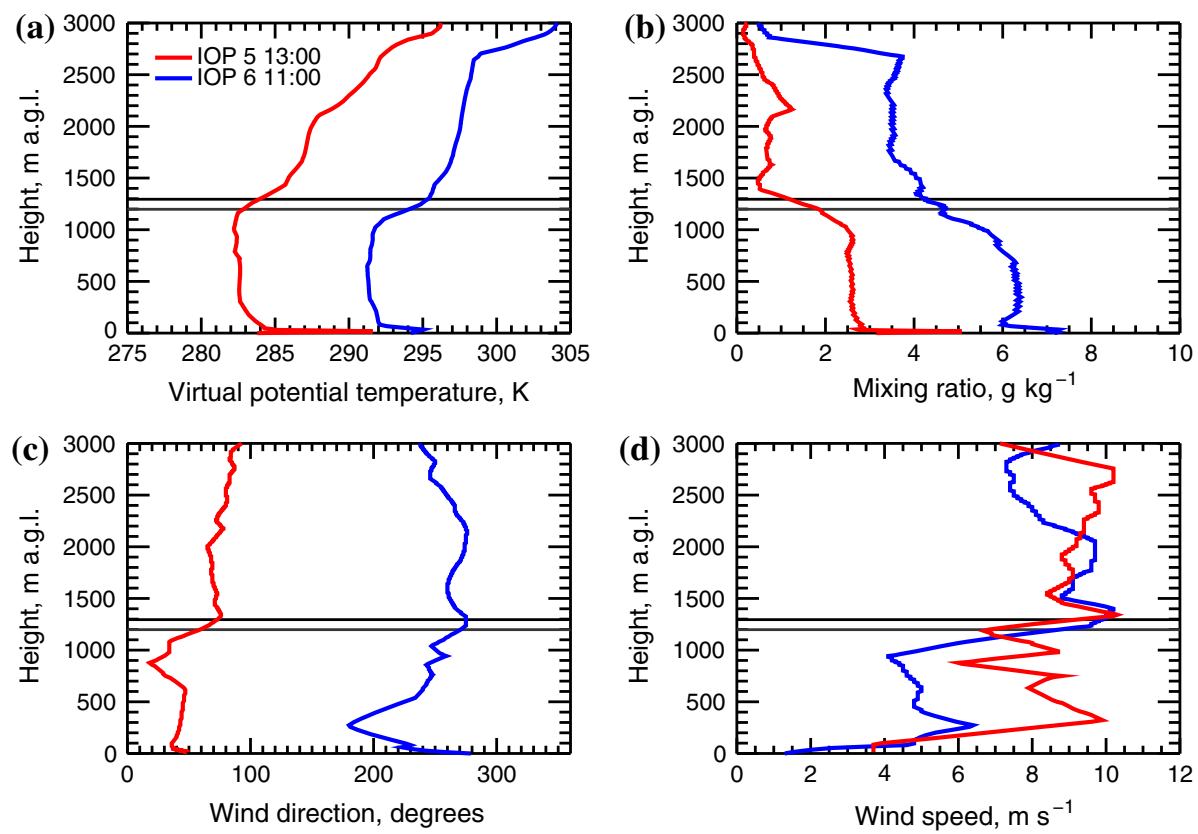

Fig. 4 Profiles of a potential temperature, $\mathbf{b}$ mixing ratio, $\mathbf{c}$ wind direction, and $\mathbf{d}$ wind speed from radiosoundings during IOP 5 (1300 UTC, red line) and IOP 6 (1100 UTC, blue line). Black and grey horizontal lines indicate the mean CBL height determined from DIAL data for the turbulence analysis periods of IOP 5 and 6 , respectively

Table 1 Main characteristics of the IOPs used in this study-IOP 5 on 20 April 2013 and IOP 6 on 24 April 2013

\begin{tabular}{lll}
\hline Parameter & IOP 5 1130-1330 UTC & IOP 6 1100-1200 UTC \\
\hline Mean CBL top height, $z_{i}(\mathrm{~m})$ & $1295 \pm 86$ & $1198 \pm 39$ \\
Convective velocity scale $\left(\mathrm{m} \mathrm{s}^{-1}\right)$ & 2.1 & 1.9 \\
Virtual potential temperature, $0.5 z_{i}(\mathrm{~K})$ & 282 & 291 \\
Virtual potential temperature, $1.2 z_{i}(\mathrm{~K})$ & 286 & 296 \\
Inversion strength $(\mathrm{K})$ & 4 & 5 \\
Mixing ratio, $0.5 z_{i}\left(\mathrm{~g} \mathrm{~kg}^{-1}\right)$ & 2.6 & 6.3 \\
Mixing ratio, $1.2 z_{i}\left(\mathrm{~g} \mathrm{~kg}^{-1}\right)$ & 0.5 & 3.5 \\
Mixing ratio diff across $z_{i}\left(\mathrm{~g} \mathrm{~kg}^{-1}\right)$ & 2.1 & 2.8 \\
Wind speed, $0.5 z_{i}\left(\mathrm{~m} \mathrm{~s}^{-1}\right)$ & 7.0 & 4.5 \\
Wind speed, $1.2 z_{i}\left(\mathrm{~m} \mathrm{~s}^{-1}\right)$ & 10.1 & 10.3 \\
Wind direction $0.5 z_{i}\left({ }^{\circ}\right)$ & 20 & 250 \\
Wind direction $1.2 z_{i}\left({ }^{\circ}\right)$ & 76 & 270 \\
Shift in wind speed across $z_{i}$ & 3.1 & 6 \\
Shift in wind direction across $z_{i}$ & 50 & 20 \\
\hline Units aregiven in sracks $^{-1}$ & &
\end{tabular}

Units are given in brackets 
$\theta_{v}$ profiles of both IOPs show a similar strong capping inversion at $z_{i}$ of around 4 and $5 \mathrm{~K}$ for IOP 5 and 6, respectively. Mixing ratio in the CBL was higher for IOP $6\left(6.3 \mathrm{~g} \mathrm{~kg}^{-1}\right)$ than for IOP $5\left(2.6 \mathrm{~g} \mathrm{~kg}^{-1}\right)$. For IOP 6 , a small peak was observed in the mixing ratio profile in the interfacial layer by the radiosonde. The prevailing flow was mainly from the north-east at the surface and veered to the east at the CBL top for IOP 5. At $z_{i}$, an increase of $4 \mathrm{~m} \mathrm{~s}^{-1}$ in wind speed and a $50^{\circ}$ shift in wind direction was found. For IOP 6 , the wind speed was lower $\left(4-6 \mathrm{~m} \mathrm{~s}^{-1}\right)$ in the CBL and a sharp increase to about $10 \mathrm{~m} \mathrm{~s}^{-1}$ was observed at $z_{i}$.

\section{Methodology: Turbulence Analyses}

Higher-order moments of remote sensing water vapour fluctuation data are an important characteristic of the turbulent structure of the CBL (Wulfmeyer 1999a, b; Kiemle et al. 1997). Lenschow et al. (2000) introduced a procedure for the estimation of higher-order moments that accounts for random instrumental noise. This method was successfully used not only to investigate higher-order moments of water vapour DIAL (Lenschow et al. 2000) but also with water vapour Raman lidar data (Wulfmeyer et al. 2010; Turner et al. 2014), and with Doppler lidar data for vertical velocity (Lenschow et al. 2000; Hogan et al. 2009; Lenschow et al. 2012; Wulfmeyer et al. 2015). More recently, temperature higher-order moments were estimated using rotational Raman lidar data (Behrendt et al. 2015). We follow Lenschow et al. (2000) for resolving the turbulent moments of humidity and for estimating instrument noise errors. A detailed description of this procedure is given in the above reference.

First, humidity data were detrended using a linear fit at each height level to remove influences of large-scale advection, synoptic processes, and the diurnal cycle and to focus on turbulent fluctuations. Time series of humidity observations $q$ were then averaged over the selected periods to obtain mean profiles $\bar{q}(z)$. Mean values were subtracted from the instantaneous humidity values $q^{\prime}$ at each height to obtain the humidity fluctuations,

$$
q^{\prime}(z, t)=q(z, t)-\bar{q}(z, t),
$$

which include the uncorrelated system noise $\varepsilon(z, t)$. It is important to remove the noise for accurate atmospheric measurements. The atmospheric variance $\sigma_{a}^{2}$ was obtained from the total variance $\sigma_{t}^{2}$ by determining and then subtracting the noise variance $\sigma_{n}^{2}$ according to

$$
\sigma_{a}^{2}=\sigma_{t}^{2}-\sigma_{n}^{2} .
$$

The water vapour DIAL instrumental noise variance was estimated by autocovariance analyses of the high-resolution humidity time series data. The autocovariance at zero lag gives the sum of the atmospheric and noise variances. The random instrumental noise is uncorrelated with the atmospheric variance and, by extrapolating a fit to the autocovariance function at non-zero lags to lag zero, the atmospheric variance was obtained,

$$
\sigma_{n}^{2}=M_{11}(0)-M_{11}(\tau \rightarrow 0) \equiv M_{11}(0)-\sigma_{a}^{2},
$$

where $\tau$ is the time lag. According to Monin and Yaglom (1971), the autocovariance function can be approximated by means of the structure function

$$
M_{11}(\tau) \approx \sigma_{a}^{2}-C \tau^{2 / 3}
$$

if atmospheric turbulence is sufficiently resolved (Lenschow et al. 2000; Wulfmeyer et al. 2010). Here, $C$ is a scaling parameter, which is related to the turbulent kinetic energy dissipation rate and the rate of the molecular destruction of humidity variance (Wulfmeyer et al. 2015). Using both Eqs. 3 and 4, the variance and noise profiles can be derived simultaneously. 
Following the notation that angular brackets denote time averaging and using $q_{a}^{\prime}$ for the atmospheric humidity fluctuation, we thus obtained the atmospheric humidity variance,

$$
\left\langle q_{a}^{\prime}(z)^{2}\right\rangle=\sigma_{a}^{2}(z) .
$$

The extrapolation of $M_{11}$ to lag zero using the structure function provides a reasonable estimation of the noise variance. It is important to determine the effective number of data points needed for the extrapolation, because too many data points cause a systematic underestimation of the atmospheric variance and vice versa. In our study, a 20-point extrapolation was used for the linear extrapolation and fit of the structure function. This is a reasonable approach because the first zero crossing of the autocovariance function $\tau_{0}=2.5 \Pi$, where $\Pi$ is the integral scale (Behrendt et al. 2015; Wulfmeyer et al. 2015),

$$
\Pi=\frac{1}{\left\langle q_{a}^{\prime 2}\right\rangle} \int_{\tau \rightarrow 0}^{\tau_{0}} M_{11}(\tau) \mathrm{d} \tau .
$$

The integral scale is a measure of the typical energy-containing eddy size in the temporal domain. Thus, by comparing the temporal resolution of the water vapour DIAL measurements with the profile of the integral scale, we can determine whether the temporal resolution is high enough to resolve the major part of the turbulent fluctuations. This was the case during both IOPs (see Sects. 5 and 6). Furthermore, we can determine whether the number of lags is reasonable for the fit of the structure function because this number should not exceed $2.5 \Pi$, which was also confirmed in our analyses. The determination of $\Pi$ is also essential to quantify the uncertainty due to limited sampling of the ensemble of turbulent fluctuations (Lenschow et al. 1994). Relationships between $\Pi$ and sampling errors of higher-order moments can be found in Lenschow et al. (1994, 2000) with further refinements by Wulfmeyer et al. (2015) and were routinely applied in our data analysis tools as well.

Similarly, the third-order moment (TOM) and the fourth-order moment (FOM) and their noise errors were computed following Lenschow et al. (2000) and Wulfmeyer et al. (2010) as,

$$
T O M=\left\langle q_{a}^{\prime}(z)^{3}\right\rangle,
$$

and

$$
F O M=\left\langle q_{a}^{\prime}(z)^{4}\right\rangle .
$$

The same number of lags was used for the extrapolations; however, due to the unknown shape of higher-order structure functions, a linear fit was used.

Skewness and kurtosis were calculated by normalizing the TOM and FOM by the variance according to

$$
S(z)=\left\langle q_{a}^{\prime}(z)^{3}\right\rangle /\left(\left\langle q_{a}^{\prime}(z)^{2}\right\rangle\right)^{3 / 2},
$$

and

$$
K(z)=\left\langle q_{a}^{\prime}(z)^{4}\right\rangle /\left(\left\langle q_{a}^{\prime}(z)^{2}\right\rangle\right)^{2} .
$$

The noise error for the accurate determination of atmospheric variance profiles is given by,

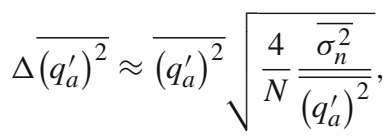


where $N$ is the number of data points during the observational period (Lenschow et al. 2000). As can be seen from Eq. 11, the relative noise error for the atmospheric variance is proportional to the square root of the ratio of instrumental noise and atmospheric variances. This becomes important for the estimation of the higher-order moments such as the fourthorder moment where the instrument noise levels must be even lower for accurate kurtosis profiles.

\section{Results}

Comparisons of the averaged absolute humidity measured with the UHOH DIAL during the selected periods and the radiosonde data are shown in Fig. 5. For IOP 5, both DIAL and radiosonde data show similar profile structures and magnitudes for absolute humidity. Good agreement is found up to the CBL top with differences smaller than $0.3 \mathrm{~g} \mathrm{~m}^{-3}$ at each altitude (Fig. 5a). In addition, in the lower free troposphere above, the differences are smaller than $0.5 \mathrm{~g} \mathrm{~m}^{-3}$. Such close agreements are not necessarily expected, mainly because the radiosonde profile is a line measurement, whereas the DIAL is a spatio-temporal average. For IOP 6 at 1100 UTC, a difference of $0.5 \mathrm{~g} \mathrm{~m}^{-3}$ is observed between DIAL and radiosonde data in the lower CBL (400-600 m). The differences were small in the middle of the CBL (600-1000 m) and increased up to $0.7 \mathrm{~g} \mathrm{~m}^{-3}$ in the interfacial layer. In the lower free troposphere above the CBL top, differences between DIAL and radiosonde data were up to $1.0 \mathrm{~g} \mathrm{~m}^{-3}$. However, the structure of the absolute humidity profile is similar for both measurements.

The absolute humidity profile of the radiosonde at 0900 UTC for IOP 6 is also shown in Fig. 5b. An elevated humid layer was present between $1200 \mathrm{~m}$ and $1400 \mathrm{~m}$ above ground level (a.g.1.) approximately $2 \mathrm{~h}$ before the period selected for the case study (Fig. 2). Between this elevated humid layer and the moist CBL below, a dry layer was found with a minimum humidity of $3.6 \mathrm{~g} \mathrm{~m}^{-3}$ at $1170 \mathrm{~m}$ AGL. By $1100 \mathrm{UTC}$, this dry layer and the elevated moist layer above had been entrained into the CBL. The mean DIAL profile at 1100 UTC shows that absolute humidity decreased from 7 to $6 \mathrm{~g} \mathrm{~m}^{-3}$ between 400 and $950 \mathrm{~m}$. A sharp decrease by $1 \mathrm{~g} \mathrm{~m}^{-3}$ was observed from 950 to $1100 \mathrm{~m}$. Around $1100-1200 \mathrm{~m}$ (near $z_{i}$ ), absolute humidity was found to be constant. Above $z_{i}$, another decrease by $2 \mathrm{~g} \mathrm{~m}^{-3}$ was observed between 1200 and $1400 \mathrm{~m}$. At the same-time, a maximum in the humidity profile was observed in the radiosonde data around $1200 \mathrm{~m}$ AGL. We believe that this absolute humidity structure influenced the higher-order moment profiles in the interfacial layer during IOP 6 (see Sect. 6). The absolute humidity gradient shows a minimum near the CBL top, as well as two maxima, one below and the other above the CBL top around 1100 and $1300 \mathrm{~m}$, respectively.

\subsection{Integral Scale}

Integral time scale $(\Pi)$ profiles were calculated using Eq. 6 and are shown for both IOPs in Fig. 6a together with their statistical uncertainty. For IOP 5, the $\Pi$ values in the CBL range between $60 \mathrm{~s}$ and $130 \mathrm{~s}$. The $\Pi$ values are larger at about $130 \mathrm{~s}$ in the lower CBL $\left(0.3 z_{i}\right)$, and decrease to $70 \mathrm{~s}$ at $0.5 z_{i}$. An increase in $\Pi$ from $70 \mathrm{~s}$ to $100 \mathrm{~s}$ up to $0.7 z_{i}$ can be seen. Another decrease to $50 \mathrm{~s}$ is found at the CBL top. Similar to IOP 5, П values range between $60 \mathrm{~s}$ and $100 \mathrm{~s}$ for IOP 6 in the CBL. In the middle of the CBL, $\Pi$ is around $100 \mathrm{~s}$ and a gradual decrease to $60 \mathrm{~s}$ with height up to the CBL top is observed. For both IOPs, an increase of $\Pi$ can be seen in the interfacial layer. According to Taylor's hypothesis of frozen turbulence 

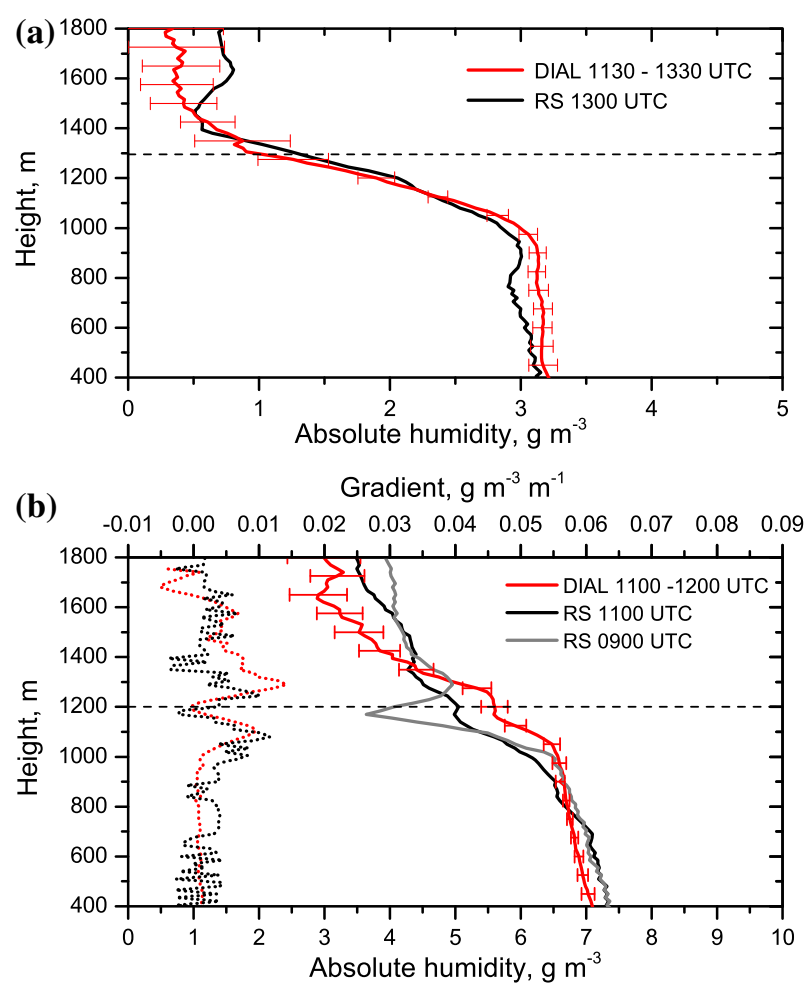

Fig. 5 Averaged DIAL absolute humidity profiles with noise errors and radiosondes during the case study periods IOP 5 (a) and IOP 6 (b), respectively. Gradients of absolute humidity profiles measured with DIAL and radiosonde at 1100 UTC for IOP 6 are also shown. Mean CBL top heights are shown as horizontal dashed lines

(Taylor 1938), the integral length scale of the eddies can be estimated by multiplying $\Pi$ with the corresponding horizontal wind speed at each height. This is valid if the mean CBL wind speed is large enough to advect the air mass through the laser beam at a time scale smaller than the eddy turnover time. The eddy turnover time for IOP 5 and IOP 6 was $1280 \mathrm{~s}$ and $805 \mathrm{~s}$, respectively. Horizontal wind profiles from the radiosondes (Fig. 3d) confirm the validity of Taylor's hypothesis for our case and are used here to estimate the integral length scale. The integral length scales normalized by the CBL depth for both IOPs are shown in Fig. 6b; both profiles roughly show a decrease in eddy size from $0.3 z_{i}$ to $0.8 z_{i}$ and an increase in the interfacial layer. For IOP 5, integral length scale for the eddy size is around $1.0 z_{i}$ in the lower CBL and decreases to $0.3 z_{i}$ at the CBL top, whereas for IOP 6 , it decreases from $0.4 z_{i}$ to $0.3 z_{i}$. The integral length scale profiles show slightly larger values around $1.0-0.6 z_{i}$ in the middle of the CBL $\left(0.3-0.5 z_{i}\right)$ for IOP 5 , compared to previous results of less than $0.4 z_{i}$ in the mid-CBL (Couvreux et al. 2005). The decrease of integral length scale with height is similar to previous observations (Kiemle et al. 1997; Wulfmeyer et al. 2010; Turner et al. 2014) and LES results (de Roode et al. 2004). Eddy size decreases with height mainly due to the entrainment of dry tropospheric air into the CBL (Couvreux et al. 2005). The values for the integral time scale are indeed several times larger than the 10-s temporal resolution of the data used, which again confirms that the resolution is high enough to resolve the inertial subrange. 

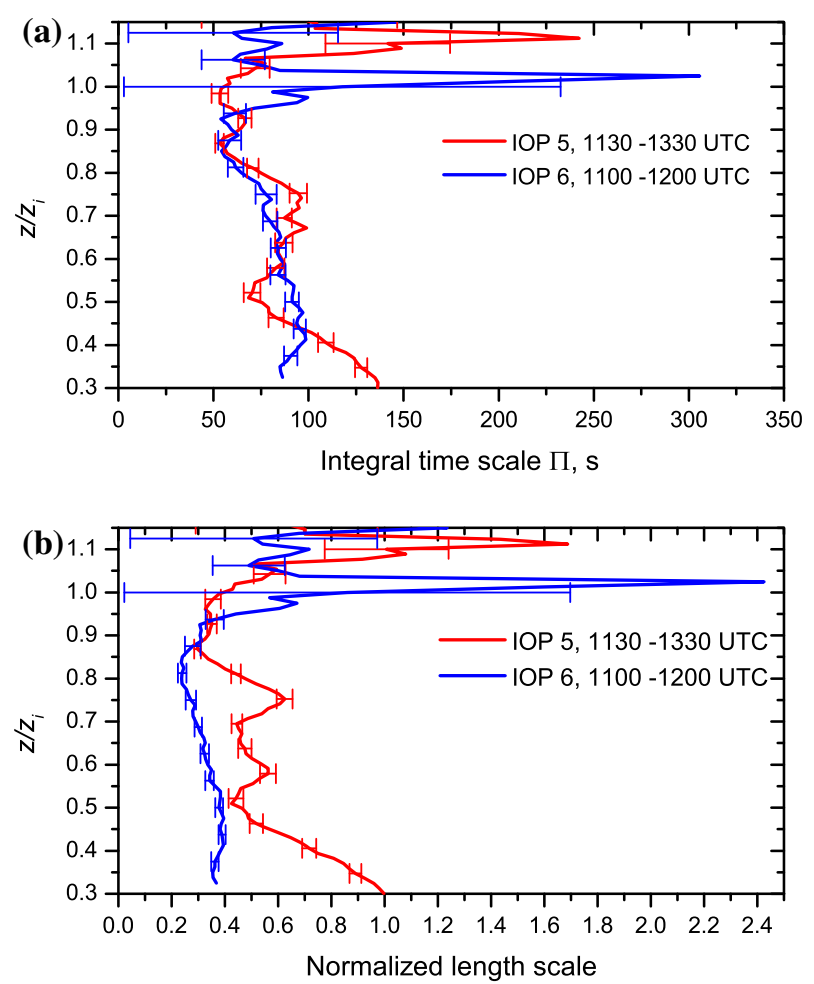

Fig. 6 a Integral time scale and $\mathbf{b}$ normalized length scale, which was obtained by dividing the integral length scale by the mean CBL top height of absolute humidity fluctuations with noise errors for the analysis periods of IOP 5 and IOP 6, respectively

\subsection{Variance}

The vertical profiles of humidity variance with noise and sampling errors for both IOPs are shown in Fig. 7. In the middle of the CBL, between $0.3 z_{i}$ and $0.8 z_{i}$, the variance is low for both IOPs with values $<0.1 \mathrm{~g}^{2} \mathrm{~m}^{-6}$. An increase with height can be seen in the variance profiles for both IOPs in the CBL with a maximum in the interfacial layer. For IOP 5, the variance increases near $z_{i}$ to a maximum of about $0.39 \pm 0.03 \pm 0.05 \mathrm{~g}^{2} \mathrm{~m}^{-6}$. The first and the second error values here and in subsequent sections denote the sampling error and noise error, respectively (see Lenschow et al. 2000). Interestingly, two peaks are observed in the interfacial layer for IOP 6: a small and broad peak of $0.18 \pm 0.03 \pm 0.01 \mathrm{~g}^{2} \mathrm{~m}^{-6}$ around $0.95 z_{i}$ and a larger peak of $0.54 \pm 0.10 \pm 0.09 \mathrm{~g}^{2} \mathrm{~m}^{-6}$ at $1.1 z_{i}$. Variance in the lower CBL is larger for IOP 6 than for IOP 5. The increase of humidity variance in the CBL with a maximum in the interfacial layer found for IOP 5 can be considered as a typical profile, because it is similar to most cases found in the literature (e.g. Moeng and Wyngaard 1989). However, the variance profile for IOP 6, with its two distinct peaks in the interfacial layer, is unusual.

\subsection{Third-order Moment and Skewness}

The third-order moment (TOM) profile measures the asymmetry in the eddy structure. The TOM profiles for IOP 5 and IOP 6 are shown in Fig. 8. For IOP 5, the TOM profile shows val- 


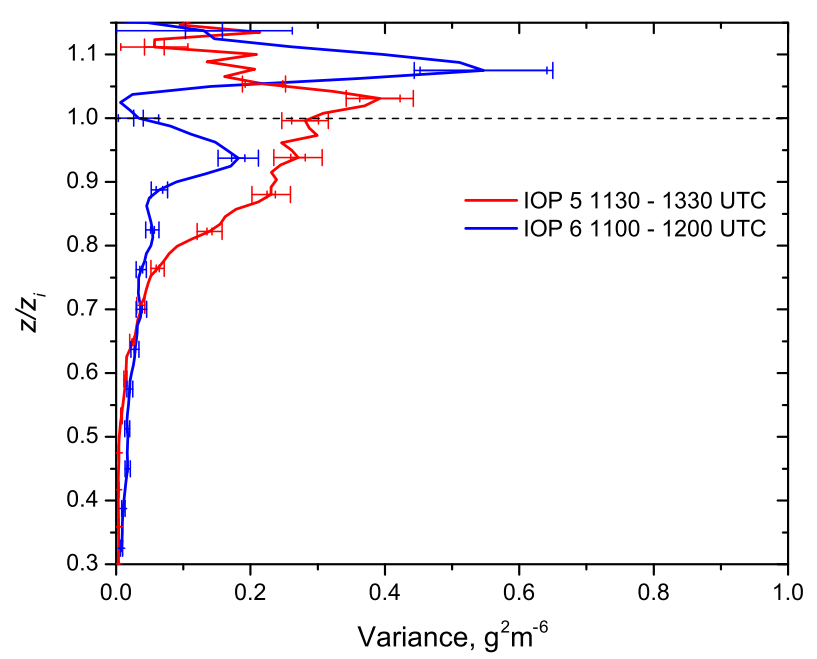

Fig. 7 Vertical profiles of absolute humidity variance with noise (small) and sampling (large) errors for the analysis periods of IOP 5 and IOP 6

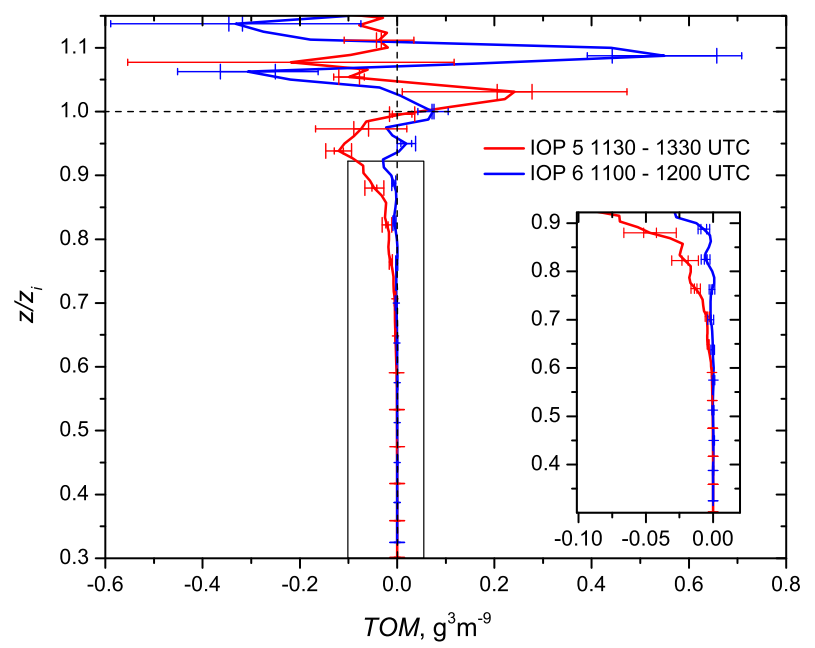

Fig. 8 Vertical profiles of third-order moment (TOM). Inset shows detail for heights of $0.3-0.9 z_{i}$

ues near zero up to $0.5 z_{i}$ and a minimum near $0.9 z_{i}$ down to $-0.12 \pm 0.02 \pm 0.01 \mathrm{~g}^{3} \mathrm{~m}^{-9}$. Near $z_{i}$, a change to positive values with a maximum $T O M$ value of $0.24 \pm 0.03 \pm 0.02 \mathrm{~g}^{3} \mathrm{~m}^{-9}$ can be seen. In the lower free troposphere, the noise errors increase and TOM is not significantly different from zero. For IOP 6, the TOM profile shows values close to zero up to $0.8 z_{i}$ and a few slightly negative data points between $0.8 z_{i}$ and $0.95 z_{i}$. Near $z_{i}$, a positive peak similar to IOP 5 is found, but with much lower TOM values of only $0.07 \pm 0.002 \pm 0.02 \mathrm{~g}^{3} \mathrm{~m}^{-9}$. A steep decrease is observed at $1.05 z_{i}$, with TOM around $-0.30 \pm 0.10 \pm 0.01 \mathrm{~g}^{3} \mathrm{~m}^{-9}$, followed by a sharp increase with a maximum of $0.54 \pm 0.12 \pm 0.10 \mathrm{~g}^{3} \mathrm{~m}^{-9}$ at $1.1 z_{i}$. Entrainment of dry downdrafts into the CBL is deeper for IOP 5 than or IOP 6 (Figs. 2, 3). In summary, the differences between the two IOPs found in the variance profiles correspond to the character- 


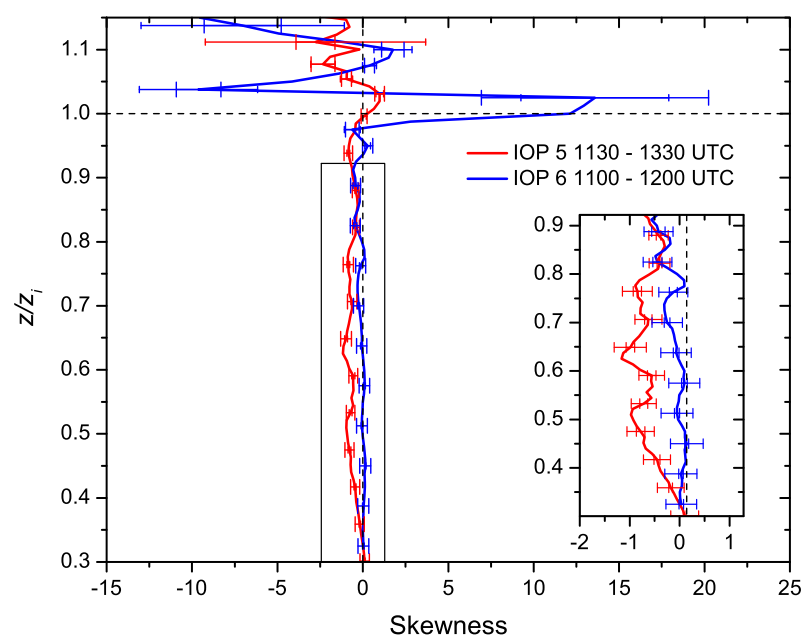

Fig. 9 Same as Fig. 8, but for skewness. Inset shows detail for heights of $0.3-1.0 z_{i}$

istics of the TOM profiles: the variance peak of IOP 5 corresponds to a TOM minimum below and a TOM maximum above, while the two peaks of IOP 6 correspond to two minima and maxima. Furthermore, the maximum variance of each peak seems to be related to the value of the corresponding TOM peaks.

Figure 9 shows the profile of skewness $S$ for IOP 5 and IOP 6, respectively. For IOP 5 , the skewness profile shows negative values with a minimum of $-1.16 \pm 0.15 \pm 0.08$ between $0.5 z_{i}$ and $0.8 z_{i}$. At $1.1 z_{i}$, the skewness profile becomes positive with a maximum $S$ of $0.98 \pm 0.25 \pm 0.18$. For IOP 6 , the humidity skewness profile shows values close to zero in the CBL up to $0.6 z_{i}$, decreasing to $-0.56 \pm 0.13 \pm 0.15$ at $0.9 z_{i}$, and then changing their sign to positive near $z_{i}$. Strongly positive values of up to $13.5 \pm 4.3 \pm 5.2$ are observed in the interfacial layer. The transition of $S$ from negative to positive is found close to $z_{i}$ for IOP 5 , whereas it occurs at $0.93 z_{i}$ for IOP 6 . A difference in absolute humidity of 2.3 and $2.8 \mathrm{~g} \mathrm{~m}^{-3}$ between the CBL and the lower free troposphere was found for IOP 5 and IOP 6, respectively. As the error of the variance adds to the error of TOM when computing $S$ (see Eq. 9), the errors of the $S$ profiles are larger than the errors in the TOM profiles, which makes it more difficult to identify positive and negative peaks. Figure 10 illustrates the findings described above with the distributions of the turbulent fluctuations at three selected heights during the two observation periods. The three height levels were chosen as follows: the first in the middle of the CBL, the second at the maximum negative value in the TOM profile below $z_{i}$, and the third above $z_{i}$, where the TOM profile has a positive peak. As expected, the distributions for both IOPs show clear differences between these three heights. In the middle of the CBL at $0.5 z_{i}$, a strong and narrow peak is observed for both IOPs, corresponding to lower variance than at the heights above. In contrast, large variances are observed just below the CBL top at around $0.9 z_{i}$. Furthermore, the distributions here are left-skewed (negative TOM) with fewer, but stronger, negative fluctuations and more, but weaker, positive fluctuations. One can identify, however, that $S$ is much smaller for IOP 5 (negative peak; thus larger in terms of absolute value) than for IOP 6, where it is close to zero. Above the CBL top, where positive TOM values are present, right-skewed distributions are observed. 

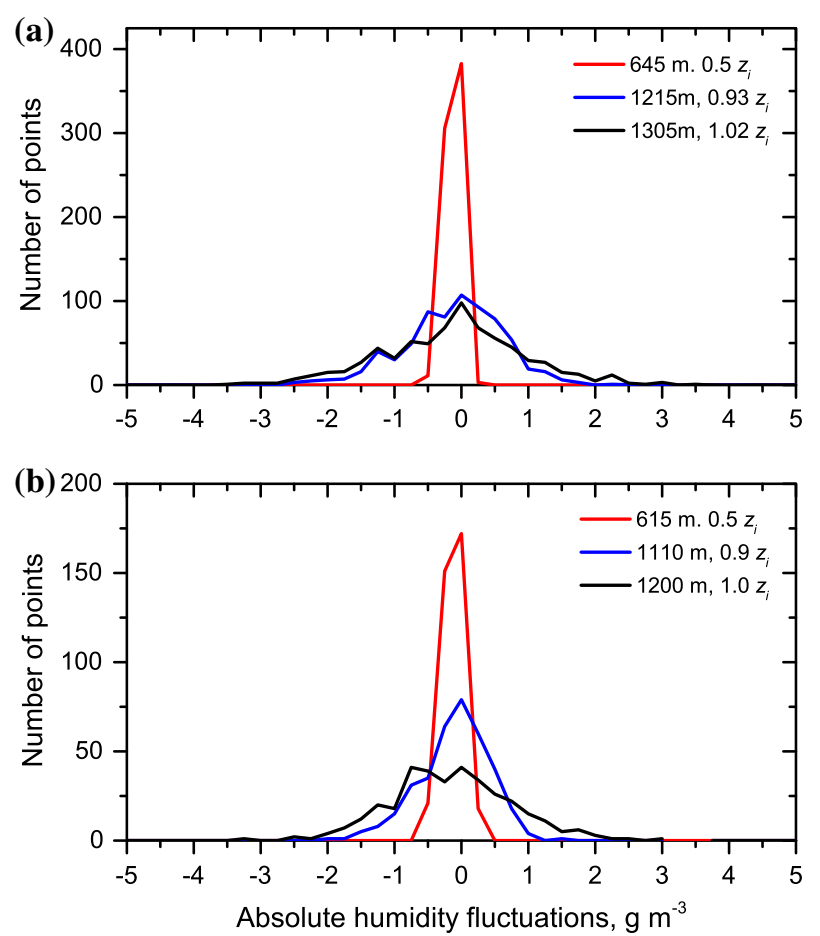

Fig. 10 Histogram of humidity turbulence fluctuations at three height levels for a IOP 5 1130-1330 UTC and b IOP 6 1100-1200 UTC

\subsection{Fourth-order Moment and Kurtosis}

Analyses of the fourth-order moment $(F O M)$ are only possible if the system noise level is very low. The FOM profiles for both IOPs are shown in Fig. 11. Results show that FOM increases with height in the CBL and maximum values are found in the interfacial layer. In case of IOP 5, a maximum FOM of $2.1 \pm 0.86 \pm 0.13 \mathrm{~g}^{4} \mathrm{~m}^{-12}$ at $1.03 z_{i}$ was observed, whereas for IOP 6 , there were two maxima at $1.01 z_{i}$ and $1.06 z_{i}$ with $1.07 \pm 0.30 \pm 0.01 \mathrm{~g}^{4} \mathrm{~m}^{-12}$ and $2.12 \pm 0.90 \pm 0.01 \mathrm{~g}^{4} \mathrm{~m}^{-12}$, respectively. Again, these features correspond to the structures of the variance profiles.

Kurtosis $(K)$ is a measure of the peakedness of the distribution, with a $K$ value of three representing a Gaussian distribution. In addition, for turbulence studies, $K$ values of less than three indicate that turbulence is frequent and the degree of mixing is large. Vertical profiles for $K$ are shown in Fig. 12. For IOP 5, $K$ values in the CBL are around three, which is the kurtosis value of a mesokurtic (Gaussian) distribution. For IOP $6, K$ values in the CBL are smaller than for IOP 5, with values of about two. Thus, the distributions are slightly platykurtic $(K<3)$ for IOP 6 and show broader peaks but fewer large fluctuations. In the interfacial layer, $K$ values increase for both IOPs, which shows that the distributions of the turbulent humidity fluctuations are leptokurtic $(K>3)$. Above $1.0 z_{i}$, the noise of the $K$ profiles increases, because humidity is much lower in the free troposphere than in the CBL. Hence, no reliable estimates of kurtosis are possible above $z_{i}$. Similar to TOM and $S$ values, the noise of the variance profile increases the noise for the $K$ values compared to FOM values, so that the height dependence is better seen in the FOM profile than in the $K$ profile. 


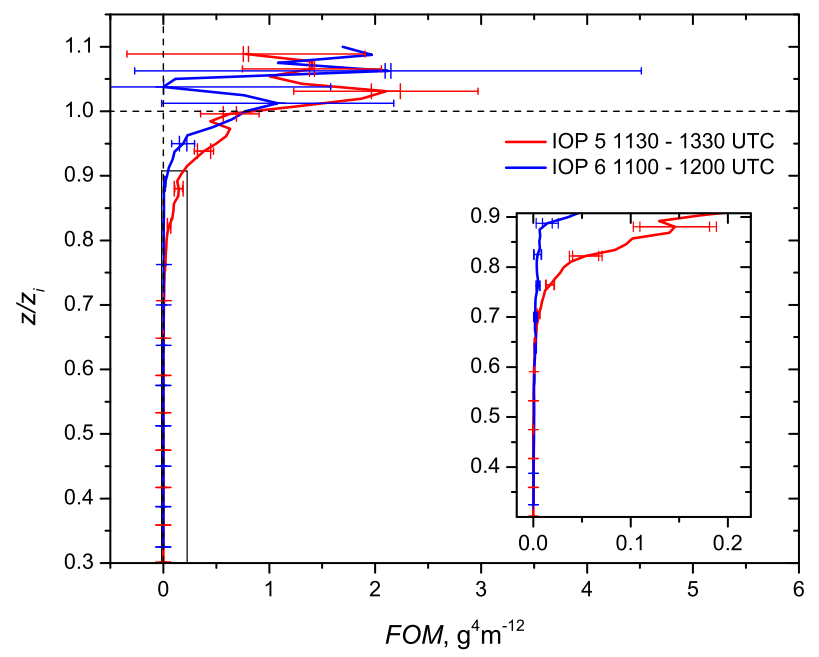

Fig. 11 Same as Fig. 8, but for fourth-order moment (FOM)

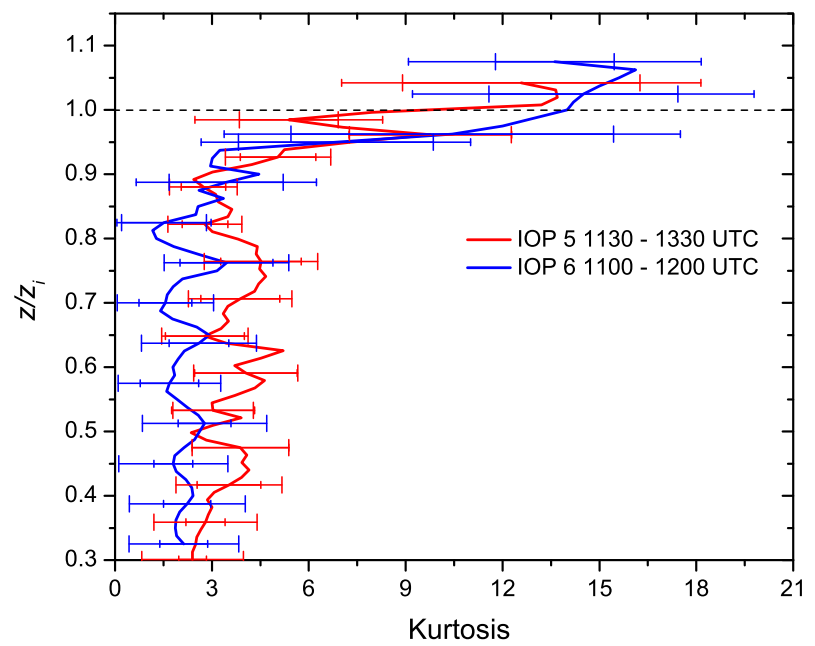

Fig. 12 Same as Fig. 6, but for kurtosis

\section{Discussion}

As we chose clear-sky days for our analyses, surface forcing was significant during both IOPs. Due to differences in soil moisture, flux partitioning was different for both cases. The mean surface sensible heat flux during the observation period was $36 \%$ higher during IOP $5\left(250 \mathrm{~W} \mathrm{~m}^{-2}\right)$ than during IOP $6\left(184 \mathrm{~W} \mathrm{~m}^{-2}\right)$. The latent heat flux at the ground showed the opposite behaviour and was 2.3 times larger during IOP $6\left(210 \mathrm{~W} \mathrm{~m}^{-2}\right)$ than during IOP $5\left(90 \mathrm{~W} \mathrm{~m}^{-2}\right)$. Related to the differences in sensible heat flux, the mean CBL height during local noon was about $100 \mathrm{~m}$ higher during IOP $5(1295 \mathrm{~m})$ than during IOP 6 (1200 m). At the CBL top, similar decreases of 2.3 and $2.8 \mathrm{~g} \mathrm{~m}^{-3}$ (corresponding to a $22 \%$ difference) were found in the absolute humidity profiles for IOP 5 and 6 , respectively. In the following 
paragraphs, we discuss whether these differences in the characteristics of the boundary layer influence the results of the turbulence analysis of the moisture fluctuations.

Because the detailed values of the integral length scale depend on the horizontal wind, these scales cannot be readily compared between different studies; however, the profile shapes can be compared. The integral time scales $(\Pi)$ show similar values for both cases. The profiles for both IOPs show a decreasing trend from $0.4 z_{i}$ up to $0.9 z_{i}$. Such a decrease has already been described in previous studies based on observations (Kiemle et al. 1997; Lenschow et al. 2000; Wulfmeyer et al. 2010) and on LES (Couvreux et al. 2005). The reason for the existence of this structure is that eddy size decreases with height from the middle CBL towards the CBL top due to a loss of buoyancy and entrainment of dry air.

Variance is found to be at a maximum in the interfacial layer for both cases discussed here. Similar to the integral time scale profile, the increase of humidity variance in the CBL with a maximum in the interfacial layer has already been discussed in previous studies, either based on LES (Deardorff 1974; Moeng and Wyngaard 1984; Sullivan et al. 1998; Moene et al. 2006; Couvreux et al. 2007) or on observations (Kiemle et al. 1997; Lenschow et al. 2000; Wulfmeyer et al. 2010). However, with our instruments, the increase of variance can be measured with unprecedented accuracy for a remote sensing system (see Fig. 7). The reason for the variance maximum in the interfacial layer is that the dry air from the lower free troposphere is mixed here most dominantly with the moist CBL air. Wind shear can also contribute to the variance production at $z_{i}$ (Jiang et al. 2010). Wind shear was present at $z_{i}$ for both our cases, and thus we believe that this effect was similar for both IOPs.

For IOP 6, however, we found two variance peaks at the CBL top. As revealed by the radiosonde profiles of 0900 UTC and 1100 UTC and by the DIAL measurements, an elevated moist layer above a dry layer was entrained into the CBL during this IOP. This process seems to be responsible for the differences found in the higher-order-moment profiles. The double-layer humidity profile present during IOP 6 resulted in two gradients, one of $0.0091 \mathrm{~g} \mathrm{~m}^{-3} \mathrm{~m}^{-1}$ at $0.95 z_{i}$ and the other of $0.014 \mathrm{~g} \mathrm{~m}^{-3} \mathrm{~m}^{-1}$ at $1.0 z_{i}$. A smaller variance peak of $0.18 \pm 0.03 \pm 0.01 \mathrm{~g}^{2} \mathrm{~m}^{-6}$ was found for the small gradient at $0.95 z_{i}$, while a larger variance peak of $0.54 \pm 0.10 \pm 0.09 \mathrm{~g}^{2} \mathrm{~m}^{-6}$ was found at $1.1 z_{i}$, where the larger gradient was present (Fig. 5).

Previously, a secondary maximum in the variance profile was discussed based on LES of trapped waves in the inversion layer (Deardorff 1974; Moeng and Wyngaard 1984). Moderate to strong wind shear could result in wave activity at the CBL top, but we see no indication of waves for either of our cases, neither in the time-height cross-sections of humidity nor in the range-corrected offline backscatter signals (figures not shown). Thus, we conclude that the entrainment of an elevated moist layer into the CBL explains the unusual variance profile of IOP 6.

The profiles of third-order moment and skewness $S$ are related to the structures found in the variance profiles. The third-order moment profile for IOP 5 shows a negative and a positive peak below and above the CBL top, respectively. This is due to the asymmetry in the fluctuations, namely a few very dry but many slightly moist fluctuations in the upper CBL due to dry air entrainment. At the same time, there is an opposite asymmetry in the lower free troposphere above with a few very moist but many slightly dry fluctuations due to overshooting thermals. Some previous studies have reported on this typical humidity skewness profile in the CBL (Mahrt 1991; Weckwerth et al. 1996; Couvreux et al. 2005, 2007; Turner et al. 2014).

Mahrt (1991) highlighted the fact that the signs of TOM and skewness (which are the same) are positive when the surface moisture flux is larger than the flux generated at the CBL top (in the opposite case, both are negative). Thus, the mean moisture tendency in the 
boundary layer, namely moistening or entrainment-drying, is related to the signs of skewness and TOM. Furthermore, the strength of this tendency can be related to the absolute skewness values.

For IOP 5, a negative skewness of about -1 was found inside the CBL, which reflects an entrainment drying boundary layer. For IOP 6, lower skewness values were found (zero in the middle of the $\mathrm{CBL}$ and about -0.5 in the upper $\mathrm{CBL}$ ). Thus, the moisture tendency for IOP was weaker. Indeed, the latent heat flux at the surface was much higher for IOP 6 than for IOP 5. Furthermore, the entrainment fluxes at the CBL top were either similar for both cases (as the moisture gradients at the CBL top were similar) or larger for IOP 5. The latter interpretation is supported by the difference in the variance profiles of both cases in the upper CBL. Here, the variances are significantly larger for IOP 5 than for IOP 6 , related to a likely larger transport of moisture variance deeper downward into the CBL and thus larger upward latent heat flux. In summary, IOP 5 presents a case for an entrainment-drying boundary layer, while IOP 6 is a case for a CBL without much moisture tendency that is neither drying nor moistening but for which the latent heat flux generated at the surface is transported upward and balanced by the entrainment of dry air at the interfacial layer.

Precise low-noise measurements in the CBL are needed for reliable estimates of the fourth-order moment and kurtosis (Lenschow et al. 2000; Wulfmeyer et al. 2010). Here, as shown in our case study, high power ground-based DIAL offers such humidity data up to the interfacial layer. Fourth-order moment values near zero were observed up to the mid-CBL, but a steep increase is found in the interfacial layer for both cases. To the best of our knowledge, previous results on humidity fourth-order moment were only shown by Lenschow et al. (2000) over a marine CBL. A similar profile was reported by these authors with an increase in the interfacial layer. The sub-structure of the FOM profiles followed the variance profiles found in both cases: the distributions become leptokurtic at the heights of variance peaks. In the middle CBL, Lenschow et al. (2000) found a mesokurtic distribution; we found the same for IOP 5, whereas for IOP 6, a slightly platykurtic distribution was found. This confirms that a mesokurtic distribution can be considered typical for an entrainment-drying CBL. Furthermore, it seems that the slightly platykurtic distribution of IOP 6 represents a CBL without moisture tendency.

\section{Conclusions}

Turbulent humidity fluctuations in the CBL including the interfacial layer were investigated by deriving the higher-order moments from UHOH DIAL data collected during the HOPE campaign. Two periods around noon under clear-sky conditions were identified and reliable profiles of up to the fourth-order moment were obtained for humidity with unprecedented precision. This permitted a very accurate measurement of the variance profile gradient from the mixed layer to the interfacial layer.

The integral-time-scale profiles show a decrease towards the top of the CBL, with values between 60 and $130 \mathrm{~s}$ in both cases. Variance was found to be at a maximum in the interfacial layer for both cases but, while one peak is present for IOP 5, two maxima can be observed for IOP 6 . We believe that the presence of two maxima for IOP 6 is due to the presence of an elevated humid layer in the lower troposphere that was entrained into the CBL. Larger variance was found in the interfacial layer, when a larger humidity gradient at the CBL top existed. Similarity relationships suggest a dependence on other CBL characteristics and we suggest that future validation studies include these additional variables (Wulfmeyer et al. 2015). 
These relationships, if validated with new observations, will be very important components of improved turbulent parametrization schemes and for advanced comparisons with LES.

Significant differences are present in the TOM and $S$ profiles for both cases. The TOM profiles show a negative and a positive peak below and above each variance maximum. For IOP 5, negative $S$ values occur in the middle of the CBL, which indicates that the CBL is drying by entrainment. Near-zero $S$ was found in the middle of the CBL for IOP 6 . Thus, we conclude that, in this case, the CBL humidity budget was in balance between the latent heat flux at the surface and the entrainment flux at the interfacial layer. For both cases, nearly zero FOM was observed in the CBL but a steep increase was found in the interfacial layer. The sub-structure of the FOM profiles again follows the variance profiles. The distributions become leptokurtic in the heights of variance peaks. The mesokurtic distribution found for IOP 5 may be typical of an entrainment-drying CBL, while the slightly platykurtic distribution of IOP 6 may be representative of a CBL where strong surface evaporation is balanced by entrainment.

These results demonstrate that high-resolution humidity data obtained with the UHOH DIAL provide new insights into the turbulence structure in the CBL and interfacial layer. The importance of subgrid-scale variability of humidity transport between the CBL and cloud layers for improving cloud-resolving model outputs was recently discussed by Moeng and Arakawa (2012).

Acknowledgments The HOPE campaign was funded by the German Research Ministry under the project number 01LK1212A. We thank KIT and the University of Cologne for performing the radiosonde launches during HOPE. We also thank Norbert Kalthoff, Martin Kohler, and all KITCube team members for providing the energy balance station data at the measurement site. We thank ECMWF for providing the analysis data during the measurement period and Thomas Schwitalla for kindly providing the figures of the ECMWF analyses. We would like to thank the three anonymous reviewers for their constructive comments.

Open Access This article is distributed under the terms of the Creative Commons Attribution 4.0 International License (http://creativecommons.org/licenses/by/4.0/), which permits unrestricted use, distribution, and reproduction in any medium, provided you give appropriate credit to the original author(s) and the source, provide a link to the Creative Commons license, and indicate if changes were made.

\section{References}

Ansmann A (1985) Errors in ground-based water-vapor DIAL measurements due to Doppler-broadened Rayleigh backscattering. Appl Opt 24:3476-3480

Ansmann A, Bösenberg J (1987) Correction scheme for spectral broadening by Rayleigh scattering in differential absorption lidar measurements of water vapor in the troposphere. Appl Opt 26:3026-3032

Behrendt A, Pal S, Aoshima F, Bender M, Blyth A, Corsmeier U, Cuesta J, Dick G, Dorninger M, Flamant C, Di Girolamo P, Gorgas T, Huang Y, Kalthoff N, Khodayar S, Mannstein H, Träumner K, Wieser A, Wulfmeyer V (2011) Observation of convection initiation processes with a suite of state-of-the-art research instruments during COPS IOP8b. Q J R Meteorol Soc 137(S1):81-100

Behrendt A, Wulfmeyer V, Hammann E, Muppa SK, Pal S (2015) Profiles of second to fourth- order moments of turbulent temperature fluctuations in the convective boundary layer: First measurements with rotational Raman lidar. Atmos Chem Phys 15:5485-5500

Bennett LJ, Weckwerth TM, Blyth AM, Geerts B, Miao Q, Richardson YP (2010) Observations of the evolution of the nocturnal and convective boundary layers and the structure of the open-celled convection on 14 June 2002. Mon Weather Rev 138:2589-2607

Bhawar R, Di Girolamo P, Summa D, Flamant C, Althausen D, Behrendt A, Kiemle C, Bosser P, Cacciani M, Champollion C, Di Iorio T, Engelmann R, Herold C, Pal S, Riede A, Wirth M, Wulfmeyer V (2011) The water vapour intercomparison effort in the framework of the convective and orographically-induced precipitation study: air-borne-to-ground-based and airborne-to-airborne lidar systems. COPS Special Issue Q J R Meteorol Soc 137:325-348 
Conzemius RJ, Fedorovich E (2006) Dynamics of sheared convective boundary layer entrainment. Part I: Methodological background and large eddy simulations. J Atmos Sci 63:1151-1178

Corsmeier U, Kalthoff N, Barthlott Ch, Behrendt A, Di Girolamo P, Dorninger M, Aoshima F, Handwerker J, Kottmeier Ch, Mahlke H, St Mobbs, Vaughan G, Wickert J, Wulfmeyer V (2011) Processes driving deep convection over complex terrain: a multi-scale analysis of observations from COPS IOP 9c. Q J R Meteorol Soc 137:137-155

Couvreux F, Guichard F, Redelsperger JL, Kiemle C, Masson V, Lafore JP, Flamant C (2005) Water vapour variability within a convective boundary layer assessed by Large Eddy Simulations and IHOP_2002 observations. Q J R Meteorol Soc 131:2665-2693

Couvreux F, Guichard F, Masson V, Redelsperger JL (2007) Negative water vapour skewness and dry tongues in the convective boundary layer: observations and large-eddy simulation budget analysis. Bound-Layer Meteorol 123(2):269-294

Davis KJ, Gamage N, Hagelberg CR, Kiemle C, Lenschow DH, Sullivan PP (2000) An objective method for deriving atmospheric structure from airborne lidar observations. J Atmos Ocean Technol 17:1455-1468

Deardorff JW (1974) Three-dimensional numerical study of turbulence in an entraining mixed layer. BoundLayer Meteorol 7:199-226

Deardorff JW, Willis GE, Stockton BH (1980) Laboratory studies of the entrainment zone of a convectively mixed layer. J Fluid Mech 100:41-64

de Roode SR, Duynkerke PG, Jonker HJJ (2004) Large-eddy simulation: how large is large enough? J Atmos Sci 61:403-421

Fedorovich E, Conzemius R (2008) Effects of wind shear on the atmospheric convective boundary-layer structure and evolution. Acta Geophys 56:114-141

Fernald FG (1984) Analysis of atmospheric lidar observations: some comments. Appl Opt 23:652-653

Grossman RL, Gamage N (1995) Moisture flux and mixing processes in the daytime continental convective boundary layer. J Geophys Res 100:25665-25674

Giez A, Ehret G, Schwiesow RL, Davis KJ, Lenschow DH (1999) Water vapor flux measurements from ground-based vertically pointed water vapor differential absorption and doppler lidars. J Atmos Ocean Technol 16:237-250

Hammann E, Behrendt A, Le Mounier F, Wulfmeyer V (2015) Temperature profiling of the atmospheric boundary layer with rotational Raman Lidar during the $\mathrm{HD}(\mathrm{CP}) 2$ observational prototype experiment. Atmos Chem Phys 15:2867-2881

Hogan RJ, Grant ALM, Illingworth AJ, Pearson GN, O’Conner EJ (2009) Vertical velocity variance and skewness in clear and cloud-topped boundary layers as revealed by Doppler lidars. Q J R Meteorol Soc 135:635-643

Ismail S, Browell EV (1989) Airborne and spaceborne lidar measurements of water vapor profiles: a sensitivity analysis. Appl Opt 28:3603-3615

Jiang Q, Doyle JD, Grubisic V, Smith RB (2010) Turbulence characteristics in an elevated shear layer over Owens valley. J Atmos Sci 67:2355-2371

Kaimal JC, Wyngaard JC, Haugen DA, Cote OR, Izumi Y, Caughey SJ, Readings CJ (1976) Turbulence structure in the CBL. J Atmos Sci 33:2152-2169

Kalthoff N, Adler B, Wieser A, Kohler M, Träumner K, Handwerker J, Corsmeier U, Khodayar S, Lambert D, Kopmann A, Kunka N, Dick G, Ramatschi M, Wickert J, Kottmeier C (2013) Kitcube-a mobile observation platform for convection studies deployed during HyMeX. Meteorol Z 22(6):633-647

Kiemle C, Ehret G, Giez A, Davis KJ, Lenschow DH, Oncley SP (1997) Estimation of boundary layer humidity fluxes and statistics from airborne differential absorption lidar (DIAL). J Geophys Res 102(D24):2918929203

Lenschow DH, Mann J, Kristensen L (1994) How long is long enough when measuring fluxes and other turbulence statistics? J Atmos Ocean Technol 11:661-673

Lenschow DH, Wulfmeyer V, Senff C (2000) Measuring second-through fourth-order moments in noisy data. J Atmos Oceanic Tech 17(10):1330-1347

Lenschow DH, Lothon M, Mayor SD, Sullivan PP, Canut G (2012) A comparison of higher-order vertical velocity moments in the convective boundary layer from lidar with in situ measurements and large-eddy simulation. Bound-Layer Meteorol 143:107-123

Mahrt L (1976) Mixed layer moisture structure. Mon Weather Rev 104:1403-1407

Mahrt L (1991) Boundary-layer moisture regimes. Q J R Meteorol Soc 117:151-176

Moene AF, Michels BI, Holtslag AAM (2006) Scaling variances of scalars in a convective boundary layer under different entrainment regimes. Bound-Layer Meteorol 120:257-274

Moeng CH, Arakawa A (2012) Representation of boundary layer moisture transport in cloud-resolving models. Mon Weather Rev 140:3682-3698 
Moeng CH, Wyngaard JC (1984) Statistics of conservative scalars in the convective boundary layer. J Atmos Sci 41:3161-3169

Moeng CH, Wyngaard JC (1989) Evaluation of turbulent transport and dissipation closures in second order modelling. J Atmos Sci 46:2311-2330

Monin AS, Yaglom AM (1971) Statistical fluid mechanics, vol 1. MIT Press, Cambridge 782 pp

Pal S, Behrendt A, Wulfmeyer V (2010) Elastic-backscatter-lidar-based characterization of the convective boundary layer and investigation of related statistics. Ann Geophys 28:825-847

Richard E, Buzzi A, Zängl G (2007) Quantitative precipitation forecasting in the Alps: the advances achieved by the Mesoscale Alpine Programme. Q J R Meteorol Soc 133:831-846

Savitzky A, Golay MJE (1964) Smoothing and differentiation of data by simplified least squares procedures. Anal Chem 36:1627-1639

Sorbjan Z (1996) Effects caused by varying the strength of the capping inversion based on a large eddy simulation model of the shear-free convective boundary layer. J Atmos Sci 53(14):2015-2024

Sorbjan Z (1999) Similarity of scalar fields in the convective boundary layer. J Atmos Sci 56:2212-2221

Sorbjan Z (2005) Statistics of scalar fields in the atmospheric boundary layer based on large-eddy simulations. Part I: Free convection. Bound-Layer Meteorol 116:467-486

Sorbjan Z (2006) Statistics of scalar fields in the atmospheric boundary layer based on large-eddy simulations. Part II: Forced convection. Bound-Layer Meteorol 119:57-79

Stevens B, Bony S (2013) What are climate models missing? Science 340:1053-1054

Stevens B, Lenschow DH (2001) Observations, experiments and large-eddy simulations. Bull Am Meteorol Soc 82(2):283-294

Stull RB (1988) An introduction to boundary layer meteorology. Kluwer Academic Publisher, Dordrecht, 688 pp

Sullivan PP, Moeng CH, Stevens B, Lenschow DH, Mayor SD (1998) Structure of the entrainment zone capping the convective atmospheric boundary layer. J Atmos Sci 55:3042-3064

Sullivan PP, Patton EG (2011) The effect of mesh resolution on convective boundary layer statistics and structures generated by large-eddy simulation. J Atmos Sci 68:2395-2415

Späth F, Behrendt A, Muppa SK, Metzendorf S, Riede A, Wulfmeyer V (2015) Water vapor heterogenties analysis with a scanning differential absorption lidar. In: preparation 2015

Taylor GI (1938) The spectrum of turbulence. Proc R Soc 67:16-20

Träumner K, Damian Th, Stawiarski Ch, Wieser, A (2014) Turbulent structures and coherence in the atmospheric surface layer. Bound-Layer Meteorol doi:10.1007/s10546-014-9967-6

Turner DD, Ferrare RA, Wulfmeyer V, Scarino AJ (2014) Aircraft evaluation of ground based Raman lidar water vapor turbulence profiles in convective mixed layers. J Atmos Ocean Tech 31:1078-1088

Van Heerwaarden CC, Vila J, Moene AF, Holtslag AAM (2009) Interactions between dryair entrainment, surface evaporation and convective boundary-layer development. Q J R Meteorol Soc 135:1277-1291

Wagner G, Behrendt A, Wulfmeyer V, Späth F, Schiller M (2013) High-power Ti:sapphire laser at $820 \mathrm{~nm}$ for scanning ground-based water-vapor differential absoprtion lidar. Appl Opt 52(11):2454-2469

Weckwerth T (2000) The effect of small-scale moisture variability on thunderstrom initiation. Mon Weather Rev 128:4017-4030

Weckwerth T, Wilson JW, Wakimoto RM (1996) Thermodynamic variability within the convective boundary layer due to horizontal convective rolls. Mon Weather Rev 124:769-784

Weckwerth T, Parsons DB, Koch SE, Moore JA, LeMone MA, Demoz BB, Flamant C, Geerts B, Wang J, Feltz WF (2004) An overview of the International $\mathrm{H}_{2} \mathrm{O}$ Project (IHOP_2002) and some preliminary highlights. Bull Am Meteorol Soc 85:253-277

Wulfmeyer V (1999a) Investigation of turbulent processes in the lower troposphere with water vapor DIAL and radar-RASS. J Atmos Sci 56:1055-1076

Wulfmeyer V (1999b) Investigations of humidity skewness and variance profiles in the convective boundary layer and comparison of the latter with large eddy simulation results. J Atmos Sci 56:1077-1087

Wulfmeyer V, Bösenberg J (1998) Ground-based differential absorption lidar for water-vapor profiling: assessment of accuracy, resolution, and meteorological applications. Appl Opt 37:3825-3844

Wulfmeyer V, Pal S, Turner DD, Wagner E (2010) Can water vapour Raman Lidar resolve profiles of turbulent variables in the convective boundary layer? Bound-Layer Meteorol 136:253-284

Wulfmeyer V, Behrendt A, Kottmeier C, Corsmeier U, Barthlott C, Craig GC, Hagen M, Althausen D, Aoshima F, Arpagaus M, Bauer H-S, Bennett L, Blyth A, Brandau C, Champollion C, Crewell S, Dick G, Di Girolamo P, Dorninger M, Dufournet Y, Eigenmann R, Engelmann R, Flamant C, Foken T, Gorgas T, Grzeschik M, Handwerker J, Hauck C, Höller H, Junkermann W, Kalthoff N, Kiemle C, Klink S, König M, Krauss L, Long CN, Madonna F, Mobbs S, Neininger B, Pal S, Peters G, Pigeon G, Richard E, Rotach MW, Russchenberg H, Schwitalla T, Smith V, Steinacker R, Trentmann J, Turner DD, van Baelen J, Vogt S, Volkert H, Weckwerth T, Wernli H, Wieser A, Wirth M (2011) The convective and orographically 
induced precipitation study (COPS): the scientific strategy, the field phase, and first highlights. Q J R Meteorol Soc 137:3-30

Wulfmeyer V, Behrendt A, Sorbjan Z, Turner DD, Hardesty RM (2015) Determination of convective boundary layer entrainment fluxes, dissipation rates, and the molecular destruction of variances: theoretical description and a strategy for its confirmation with a novel lidar system synergy. J Atmos Sci (under review)

Wyngaard J, Brost RA (1984) Top-down and bottom-up diffusion of a scalar in the convective boundary layer. J Atmos Sci 41:102-112

Zhou B, Simon JS, Chow FK (2014) The convective boundary layer in the terra incognita. J Atmos Sci 71:2545-2563

Zhu P, Albrecht B (2002) A theoretical and observational analysis on the formation of fair-weather cumuli. J Atmos Sci 59:1983-2005 